\title{
Pulpotec Reaction in a Pediatric Patient: A Case Report
}

\author{
Mohammed Karimi D.M.D* \\ Sepideh Dental Clinic, Pediatric Department, Iran
}

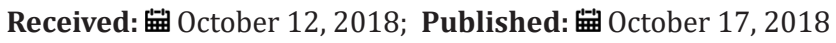

*Corresponding author: Karimi, Sepideh Dental Clinic, Pediatric Department, Iran

\begin{abstract}
Dermatological allergies can have different causes. But the most frequent one in dentistry may be associated with the chemical agents which are used in dentistry. Even though the hypersensitivity to Formalin in children not frequently is reported, but some of the researches have shown the skin reaction has happened during or after the endodontic treatments. In spite, this is still a controversy among the researchers and scientists; we present a case of skin reactions with Pulpotec in a dental clinic. To achieve the result, the patch test was used.
\end{abstract}

Keywords: Pulpotec; Dermatological Allergies; Formalin; Endodontic Treatments

\section{Introduction}

Pulpotec is a radiopaque, non-resorbable dental paste for the treatment of pulpits by pulpotomy in vital molars, both permanent and deciduous, and due to its antibacterial activity, has proved as efficient in vital pulpotomy in children [1]. The Compositions of Pulpotec are including powder (Iodoform, Polyoxymethylene, and excipient) and liquid (Phenol, Guaiacol, Formaldehyde, Dexamethasone Acetate, and excipient) [2]. Hypersensitivity to Formaldehyde, especially in root canal therapy, has been documented in the research paper [3]. In the dental literature, 28 patients with immediate symptoms to formaldehyde containing root canal compounds have been described [4]. For diagnosis of Pulpotec hypersensitivity, a comprehensive study of the signs and the symptoms of this dermatitis reaction are necessary. Noteworthy, application of the Patch Test using the aqueous solution of formalin can prove the positive result and give the final diagnosis.

\section{Mechanisms of Actions of Formalin}

Formaldehyde also is known as formalin, is a gaseous body, obtained by the oxidation of methylic alcohol at a moderately high temperature. It has the chemical property of uniting with sulfurated or nitrogenous products of decay, fermentation or decomposition, forming true chemical compounds, and these compounds are in most cases antiseptic themselves. When formaldehyde is present, due to its germicidal and bactericidal powers, it combines with both the bacteria and their food, thus destroying them [5]. An aqueous solution of formaldehyde which can be useful as a disinfectant, it kills most bacteria and fungi [6]. Formaldehyde is used as biocides in some products such as cosmetics, or even mouthwashes. Although to some extent not normally considered to be harmful, they might cause allergic contact dermatitis in certain individuals [7].

\section{Case Presentation}

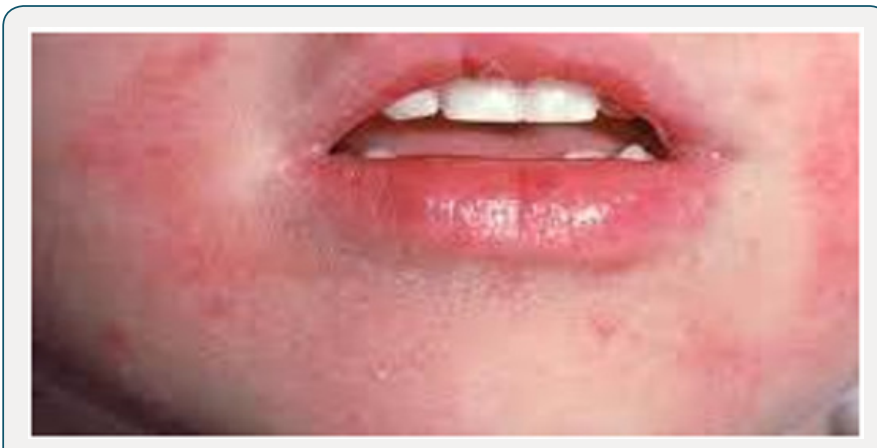

Figure 1: Hypersensitivity reaction on face.

A 7 -year-old boy came to the clinic one day after pulpotomy treatment. The chief complaint of the child's parents was the appearance of a large red spot with itching and dried skin on the both sides of the patient's face, on the areas of the cheek, under the lower lip, and the chin. As the mother explained, these symptoms occurred immediately on the kid's face one day after the treatment was completed. The patient had no history of medical illness before. 
Of course, it should be explained this treatment was not the first dental work, and the patient had no history or complications of any previous dental work (Figure 1).

\section{Discussion}

The main purpose of this case report was to study the hypersensitivity of Pulpotec as a good material which is used in children's pulpotomy. Schnuch A et al. [8] analyzed the sensitization pattern and patch-test results of more than 30,000 healthcare workers in difficult occupations (nurses, dental nurses, dental technicians, dentists, physicians, masseurs etc. Significantly increased sensitization rates common to the healthcare sector were found for the vaccine preservative Thiomersal, as well as for Glutaraldehyde, Formaldehyde and Glyoxal. The list of different occupations at risk for occupational skin diseases in healthcare sector includes mainly nurses, physicians, masseurs, dental technicians. Cases of occupational allergic contact dermatitis from formaldehyde textile finish resins were described [9-11]. Some data are available concerning allergic reactions to formaldehyde in a dental root canal compound, during and after endodontic treatment. Cases of contact urticaria from formaldehyde in a rootcanal dental paste with positive skin tests and high levels of antiformaldehyde IgE were described [12-14]. From one point of view, he antimicrobial efficiency of Pulpotec may be due to the strong antibacterial action of formaldehyde vapor, as reported by Simon et al. [15]. On the other hand, the activity of pediatric dentists can be associated with having contact with dental materials such as Eugenol, Formalin, and Pulpotec and so on. During a pulpotomy, the gloves may be Impregnate to formalin moisture, and the dentist unwished might touch the kid's cheek or face. Hence, the allergic reaction to this substance can be expected. The diagnosis of formaldehyde sensitivity is based on the symptoms and signs and a patch test using $2 \%$ formalin in aqueous solution.

\section{Conclusion}

Although these findings cannot be considered as documented proofs, they might explain this hypersensitivity to be associated with dental materials such as Pulpotec which is used in the pediatric pulpotomy. The patch test with $2 \%$ formalin is a useful procedure in the investigation of contact dermatitis.

\section{References}

1. Al SalmanKA, Al Rawi BA, Rahawy OS (2012) The Effectiveness of Using Pulpotec $®$ in Treatment of Pulpits by Pulpotomy of Vital Deciduous Molar and Vital Immature Permanent Molar. Al Rafidain Dent J 12(1): 185-190.

2. Torabinejad M, Handysides R, Khademi AA, Bakland LK (2002) Clinical implications of the smear layer in endodontics: a review. Oral Surgery, Oral Medicine, Oral Pathology, Oral Radiology, and Endodontology 94(6): 658-666.

3. Ji Hoon Jang, Seung Hyun Park, Hang Jea Jang, Sung Geun Lee, Jin Han Park, et al. (2017) A Case of Recurrent Urticaria Due to Formaldehyde Release from Root-Canal Disinfectant. Yonsei Med J 58(1): 252-254.

4. Tas E, Pletscher M, Bircher AJ (2002) IgE mediated urticaria from formaldehyde in a dental Root canal compound. J Investig Allergol Clin Immunol 12(2): 130-133.

5. Ferdinand JS Gorgas (1901) Dental Medicine. A Manual of Dental Materia Medica and Therapeutics.

6. (2018) Ingredients of Vaccines - Fact Sheet Center for Disease Control.

7. De Groot Anton C, Flyvholm Mari Ann, Lensen Gerda, Menné Torkil, Coenraads Pieter Jan (2009) Formaldehyde-releasers: relationship to formaldehyde contact allergy. Contact allergy to formaldehyde and inventory of formaldehyde-releasers. Contact Dermatitis 61(2): 63-85.

8. Schnuch A, Uter W, Geier J, Frosch PJ, Rustemeyer T (1998) Contact allergies in healthcare workers. Results from the IVDK. Acta Derm Venerol 78(5): 358-363.

9. Cockayne SE, McDonagh AJ, Gawkrodger D (2001) Occupational allergic contact dermatitis from formaldehyde resin in clothing. Contact Dermatitis 44(2): 109-110.

10. García Bracamonte B, Ortiz de Frutos FJ, Iglesias Diez L (1995) Occupational allergic contact dermatitis due to formaldehyde and textile finish resins. Contact Dermatitis. 33(2): 139-140.

11. Reich HC, Warshaw EM (2010) Allergic contact dermatitis from formaldehyde textile resins. Dermatitis 21(2): 65-76

12. Braun JJ, Zana H, Purohit A, ValfreyJ, Scherer P, et al. (2003) Anaphylactic reactions to formaldehyde in root canal sealant after endodontic treatment: four cases of anaphylactic shock and three of generalized urticaria. Allergy 58(11): 1210-1215.

13. El Sayed F, Seite Bellezza D, Sans B, Bayle Lebey P, Marguery MC, et al. (1995) Contact urticaria from formaldehydein a root-canal dental paste. Contact Dermatitis 33(5): 353.

14. Ezughah FI, Murdoch SR, Finch TM (2001) Occupational airborne allergic contact dermatitis from medium-density fiber board containing phenol-formaldehyde resin-2(PFR-2), Contact Dermatitis 5(4): 242.

15. Simon M, Van Mullem PJ, Lamers AC (1979) Antimicrobial effectiveness in endodontic therapy using Formocresol and two new alcoformol agents. Oral Surgery, Oral Medicine, Oral Pathology 47(5): 471-474. 
(C) (P) This work is licensed under Creative

To Submit Your Article Click Here: Submit Article

DOI: 10.32474/IPDOAJ.2018.02.000133

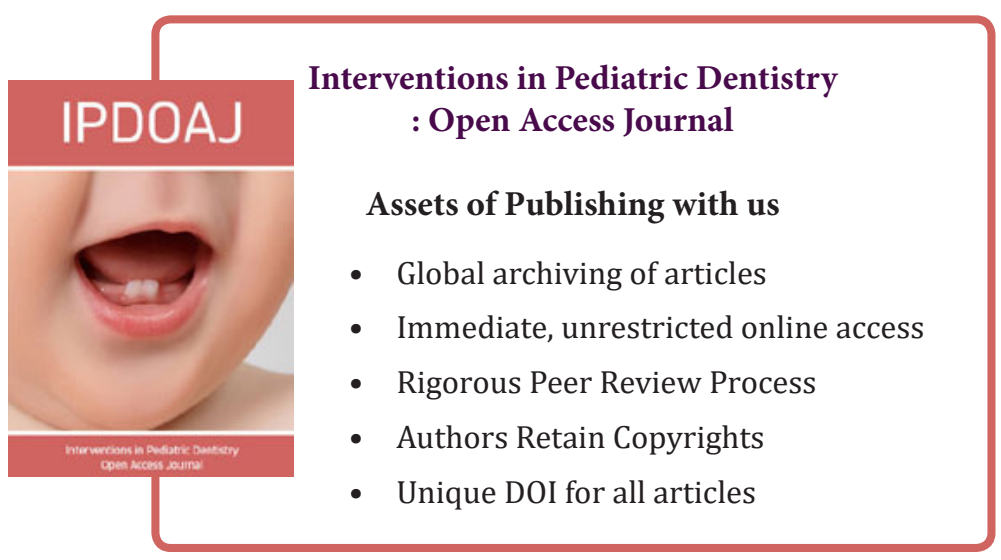

